\title{
Consumers' Active Reaction to Brands Taking Stands on Public Issues on Twitter
}

\author{
Anastasiia Berestova, Da-Yeon Kim * (D) and Sang-Yong Kim * \\ Business School, Korea University, Seoul 02841, Korea; anastasia1108@korea.ac.kr \\ * Correspondence: bellady@korea.ac.kr (D.-Y.K.); sangkim@korea.ac.kr (S.-Y.K.)
}

Citation: Berestova, A.; Kim, D.-Y.;

Kim, S.-Y. Consumers' Active

Reaction to Brands Taking Stands on Public Issues on Twitter.

Sustainability 2022, 14, 567. https://

doi.org/10.3390/su14010567

Academic Editor: Lester Johnson

Received: 9 December 2021

Accepted: 2 January 2022

Published: 5 January 2022

Publisher's Note: MDPI stays neutral with regard to jurisdictional claims in published maps and institutional affiliations.

Copyright: () 2022 by the authors. Licensee MDPI, Basel, Switzerland. This article is an open access article distributed under the terms and conditions of the Creative Commons Attribution (CC BY) license (https:// creativecommons.org/licenses/by/ $4.0 /)$.

\begin{abstract}
With the growing interest in sustainability, brands increasingly use social media not simply to advertise their products but also to share their positions on ongoing public issues. This study investigates the effect of public-issue posts on consumers' active reactions and provides comparisons between two samples-public-issue posts and all Twitter posts. After collecting data from Twitter based on tweets from official sportswear brand pages, we find that public-issue posts have a positive influence on consumers' active reaction (i.e., number of retweets, number of quotes, number of replies, and post-social search behavior). Moreover, the effect of brand activeness, which is brand social activity on Twitter, and media type (photo or video presence in a tweet) are included in the analysis. With user engagement in the public-issue post sample, the effect of the media type is not significant, whereas the effect of brand activeness is significant. This study aggregates literature on brand activism and environmental, social, and governance (ESG) criteria to propose a measurement for a public issue in a single post rather than at the corporate level. The results of this study are useful for brands of all scales taking sustainable marketing strategies and aiming to improve interactions with consumers on Twitter.
\end{abstract}

Keywords: public-issue post; taking stands on public issues; consumers' active reaction; brand activism; social media marketing; Twitter

\section{Introduction}

Social media has been critical to brands of all scales in recent years more profoundly than ever before. The growing demand for high-quality social media content and consumers' constant exposure to online advertisements have influenced brands' marketing strategies toward a more user-oriented approach. Social media has become, not only a platform to communicate with customers, but also a place for brands to express their personalities and speak up on important matters [1]. As more brands have been openly taking a stand on public issues online, consumers have started to define their purchase choices based on agreement with the brand's stand. A recent online study found that $37 \%$ of consumers express their willingness to recommend a brand to friends and family when they agree with the brand's stand [2].

Furthermore, consumers believe that taking a public stand on social and political issues benefits a brand's image, whereas the actions behind the public-issue statements can create real change in the world. However, brands need to be especially careful with the statements they post online. Social advertising is exposed to the risk of being perceived as untrustworthy and inauthentic when motivated by marketing reasons [3]. Inauthentic statements on public issues may lead to negative reactions by online users and, eventually, neglect of a brand.

Twitter is a popular platform for researching social media reactions and specific practices, such as political campaigns and social activism. Over the last year, the world has faced several global issues that everyone has been discussing actively. Consequently, \#COVID19 and \#BlackLivesMatter have become the two most often mentioned hashtags on 
Twitter [4]. With the growing interest in sustainability, topics on the need for responsible packaging and tweets combating climate change have grown significantly $(+110 \%$ and $+32 \%$, respectively) [5]. Along with posts on \#COVID19 and \#BlackLivesMatter, many brands have openly discussed current political issues (e.g., unrest in the U.S. Capitol) and socially urgent issues (e.g., racism toward the Asian community).

Twitter's audience comprises active and influential consumers. Compared with users of other social media platforms, Twitter's audience is $78 \%$ more likely to post or share about brands and $120 \%$ more likely to message a brand on social media ("Inside the discovery mindset on Twitter-and what it means for brands", 2019). It has been found that 77\% of Twitter users would share their views and recommendations, in contrast to $49 \%$ of users on other platforms [6]. Advertising campaigns on Twitter increase the "brand love" metric ( $+8 \%$ on average); one of the toughest metrics to improve [7].

The research objective of this study is to explore the effect of public-issue posts on consumers' active reactions to brands' official Twitter pages. Thus, Tweets generated by 20 large and small sportswear brands, and consumers' active reactions to Tweets, are used for empirical analysis. Consumer's active reactions are examined through Twitter engagement metrics - retweets, quotes, and replies - and a new variable proposed in this study-post-social search behavior. Public-issue posts are first examined through the constructed public-issue post index based on 10 environmental, social, and governance (ESG) criteria and issue urgency. Then, a comparative analysis of public-issue posts vs. non-public-issue posts is provided. The effect of brand activeness (i.e., brand social activity on Twitter) and media type are included in the analysis.

The current research contributes to the existing literature and managerial practice from several perspectives. It introduces a measure to evaluate public-issue posts using the commonly applied incorporated field ESG criteria. It uses the urgency of the issue metric to distinguish hot topics from general posts. An approach to measure post-social search behavior is proposed based on brand engagement on Twitter. Moreover, public-issue posts and all other posts are compared. The research examines brand activeness in the context of public issues rather than general Twitter activity. It also provides an analysis of media types included in the tweets.

\section{Theoretical Background and Hypothesis}

\subsection{Public Issue}

It is common practice for companies to align their messages with social organizations and speak up on urgent global issues to demonstrate their commitment to the environment and society [8]. The literature on brands taking a stand on public issues has not yet spread widely, with most of the research being focused on the authenticity of brands' claims in the online environment. Brand activism is the concept recently introduced in the research by Sarkar and Kotler [9] which discusses the authenticity of brands' public stances (i.e., the congruence of brand values with the brand's public position). Other definitions of brand activism are the alignment of a brand's explicit purpose with its activist marketing messaging [10] and the result of the failure of governments to address the world's most urgent problems [9]. This study addresses brand activism synonymously with the term "public issue" to describe the phenomenon of brands openly posting about social or political issues.

Brands are eager to take an open stand on public issues for several reasons. ESG investments boost brand equity value, a metric crucial for the brand's image [11]. Brands implement sustainable marketing strategies to differentiate from other brands [12] and impact customer behavior [13]. Some studies found that many consumers are more likely to buy from or boycott a brand because of its stance on a social or political issue $[14,15]$ and have demonstrated that brand activism affects consumer attitudes asymmetrically [16]. Taking a stand on public issues, or engaging in brand activism, may improve perceptions of a brand's image, improve customer loyalty, and position a brand in a separate niche from its competitors. 


\subsection{Engagement with Consumers on Twitter}

Currently, the market is witnessing an increasing rate of corporate blogs. According to Barnes et al. [17], 77\% of the Fortune 500 companies are active users of blogs as a customer communication tool. Studies found that most of those companies (89\%) use Twitter as a means of business-consumer communication.

Twitter is differentiated from other social media platforms by allowing companies to interact with their customers through all stages of the marketing process, which include marketing research (before purchase), sales promotion (purchase), and customer service (after purchase) [18]. Accordingly, Twitter is expected to facilitate more efficient and balanced channels of information inflow and outflow, increasing brand awareness and interest in a company and product overall [19]. Similarly, previous studies corroborated the hypothesis by arguing that Twitter can potentially increase traction to a company's website, which could convey a firm's message, ideology, and other detailed information more efficiently [20,21]. Thus, Twitter can be operationalized by companies as a tool for more effective business-consumer communication, increased brand exposure, and enhanced relationships with customers.

With the increasing surge of active Twitter users, social media has gained value as a means of interaction between a company and its customers [22]. The attractiveness of this platform is defined by various methods of consumer engagement, including weblinks and hashtags to increase the number of retweets [23], scanning consumers' comments and implementing timely feedback [24], using popular feedback to increase exposure to products and organizational events [25] and incorporating celebrities in tweets for higher brand exposure [26].

According to Dann [27], brands often operationalize Twitter as a platform for social activism and political campaigns. These activities are instrumental in creating an illusion of physicality [28], increasing perceived connectedness with other users [29], and establishing open dialog [30]. The active engagement of marketers and consumers on Twitter has enabled companies to lead an open conversation with customers, provide feedback, and communicate humorously-possibly correlated with the phenomenon of anthropomorphism of brands by consumer [31]. Anthropomorphism is defined as associating nonhuman characteristics and activities with human traits and events [32]. Moreover, the phenomenon is prevalent among all individuals [33]. Scholars in marketing research relate the concept of anthropomorphism to a psychological mechanism of instilling human traits to brands, defined as brand personality [34].

Through effective Twitter communication, some brands can elevate their status to a personality (rather than a brand) with thoughts, opinions, and emotions [35,36]. The researchers define this phenomenon as an "entified brand" and argue that the effect can be achieved through more enhanced and effective implementation of a "brand personality" in the social media domain. Sashittal et al. [35] argued that more active interaction with customers via engagement in meaningful and intelligent conversations facilitates a brand's "entification." They hypothesize that entified brands benefit from the status by increasing their perceived authenticity and gaining celebrity-like status among Twitter users.

\subsection{Consumers' Active Reaction}

\subsubsection{Retweets, Quotes, and Replies}

Muñoz-Expósito et al. and Ingrassia et al. [37,38] determined consumer reaction on social media as valuable data that could aid companies in better understanding their customers' perception of a brand. According to that study, consumer reaction is an estimate of consumer attitudes toward the brand, helpful for approximating consumers' level of involvement and acceptance. Since the reactions can ultimately influence purchase decisions, brands attempt to engage consumers' active reactions on social media [39]. Thus, implementing a comprehensive method of consumers' active reaction designed explicitly for Twitter has significance in theoretical discussion and managerial practice. 
This study uses previous research on Twitter-specific engagement metrics-replies, retweets, quotes, and favoriting-to provide a method to measure consumers' active reaction to brands' posts on Twitter. First, Muñoz-Expósito et al. [37] estimated user participation by the number of replies to the specific tweet, approximating replies with user interaction with the post. Second, Kim et al. [40] described another measure of consumers' active reaction, the retweet, defining it as forwarding a tweet from another user to the connected followers. The importance of retweets as a measurement both for brands and researchers in the field is recognized. Third, Sotiropoulos et al. [41] described a quote as a tweet with an embedded URL of another post that includes a commentary on the said post. Finally, last type of user interaction is favoriting. Favoriting could help estimate user engagement and content endorsement but does not introduce the content to the user's extended social network and is considered a more passive metric [22].

Therefore, this study does not consider favoriting as an active reaction. Only three active user reaction metrics on Twitter were discussed further: replies, retweets, and quotes.

\subsubsection{Post-Social Search Behavior}

The WOM effect on social media has also prompted researchers to focus on consumers' post-social search activity. Consumers' post-social search behavior is one of the most active, and it has the potential to impact subsequent behavior, such as a purchase. Machleit et al. [42] proposed that brand interest leads to searching for additional information related to the brand. They refer to brand interest as an individual's degree of interest in a brand and the level of intrigue required to search for more brand-related information. Gao et al. [43] found that consumer interest in a brand increases brand-searching behavior on social media.

The social media platform is an important information WOM channel for consumer interpersonal communications about brands and products [44]. Kim et al. [40] assert that Twitter stimulates the positive effect of WOM, such as information diffusion and brand exposure. The phenomenon may occur due to the frequent one-to-one communication of a brand and its consumers, which improves business-customer relationships. In terms of facilitating search behavior and WOM, posts on Twitter include @links and \#hashtags, which create favorable conditions for high levels of exposure [45]. According to Mishne and De Rijke [46], quantitative papers should also consider the freshness of a post because it has a significant influence on measuring consumer reaction. Consequently, this study investigates Twitter post-social search behavior: the number of brand-mentions in the first $24 \mathrm{~h}$ after a tweet was posted.

This study accounts for four types of consumers' active reaction: number of retweets, number of quotes, number of replies, and post-social search behavior. Thus, we propose that:

Hypothesis 1 (H1). Public-issue posts have a positive effect on consumers' active reaction (a. \# of retweets; $b$. \# of quotes; $c$. \# of replies; $d$. post-social search behavior).

\subsection{Brand Activeness on Twitter}

A brand's activity on social media is an important concept in quantitative studies on consumer social engagement. Previous studies proposed measuring brand activity by analyzing the number of tweets posted per day and the number of current followers [20]. One study suggested using not only brands' activity on a social media platform but also brands' follower reactions to the related posts because it would reveal a more comprehensive and compound insight [47]. Brand activity is commonly used as a metric of brand interactions on Twitter that can be tracked long-term (e.g., number of followers).

However, this study considers a specific component of brand-generated tweetspublic-issue posts, which constitute a measure in the representative moment (e.g., posts on COVID-19). Due to the focus of this study on public-issue posts, we propose referring to the term "brand activeness" as the state of a brand being socially active and evaluate it 
based on the number of public-issue posts on brands' official Twitter pages tweeted in the considered period.

Hypothesis 2 (H2). Brand activeness has a positive effect on consumers' active reaction (a. \# of retweets; $b$. \# of quotes; $c$. \# of replies; $d$. post-social search behavior).

\subsection{Media Type}

Including media in a post can influence positive consumer interactions with the brand. Han et al. [48] concluded that press releases, including visual content, such as videos or photos, gain more views among social media users than those that include only text. Furthermore, the conclusion was corroborated by another study that suggested that posts containing video content are retweeted six times more often than posts with photos and three times more than posts containing GIFs [49]. Although Twitter tweets can contain three types of media (i.e., photos, videos, and GIFs), GIFs are omitted from further analysis because the number of posts containing GIFs was negligible.

Hypothesis 3 (H3). Media type ( $a$. photo; $b$. video) in a tweet has a positive effect on consumers' active reaction ( $a$. \# of retweets; $b$. \# of quotes; $c$. \# of replies; $d$. post-social search behavior).

\section{Empirical Analysis}

\subsection{Conceptual Framework}

The conceptual framework of this study is presented in Figure 1. This study attempts to explore the effect of public-issue posts on consumers' active reaction. An index to measure public-issue posts is proposed. Two control variables, brand activeness and tweet media type, are also investigated.

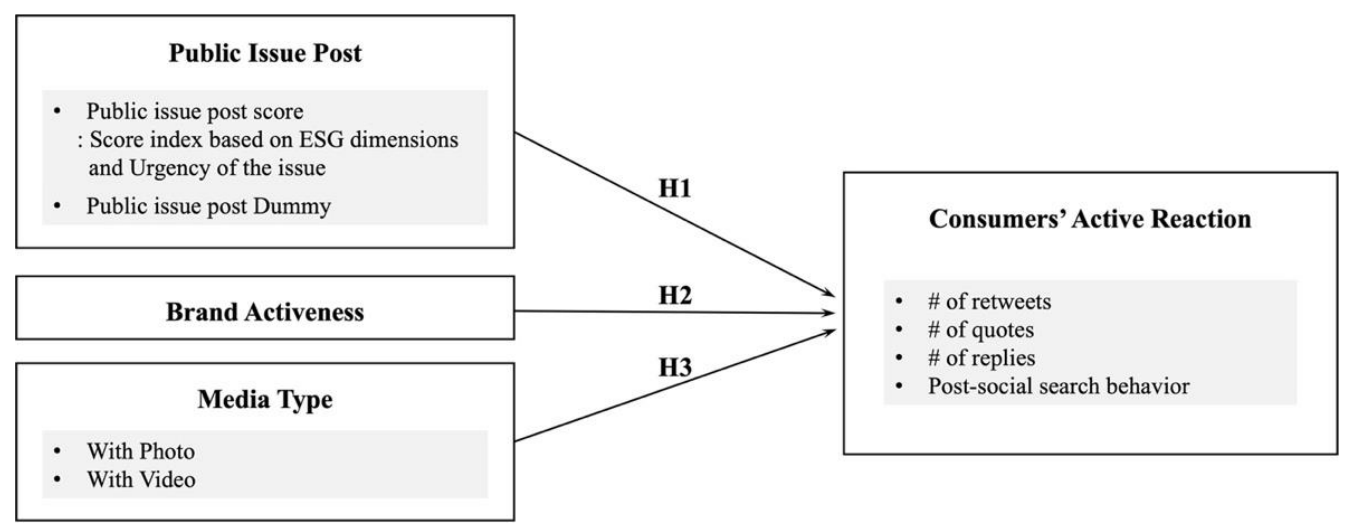

Figure 1. Conceptual Framework.

\subsection{Data}

The following empirical analysis consists of two parts. First, public-issue posts were explored using post-level data and include 143 observations (Sample 1). Second, publicissue posts were explored with other non-public-issue posts and include 1476 observations (Sample 2). Tweets were crawled from Twitter and included 20 sportswear brands, 10 large brands, and 10 small brands to ensure representativeness of the sample and explore several corporate Twitter strategies. The ranking order of the brands was determined using Global Web Index [50] sportswear brands' purchasing data. The brands' official Twitter pages or, for a brand with multiple Twitter pages, the largest pages with tweets in English, were investigated.

Table 1 introduces the brands used in this study and includes the number of followers on each brand's official Twitter page. Replies from brands to users were excluded from crawling because they do not contain information on public issues, and 116 outliers were 
removed from the second sample (tweets that have been retweeted, quoted, or replied much more than other tweets). The period of the extracted data is six months, from 1 July 2020, to 31 December 2020. Although the total number of crawled tweets included 1476 observations, only $10 \%$ of the tweets were public-issue posts ( 143 observations). The list of sportswear brands and numbers of followers on Twitter pages are presented in Table 1.

Table 1. Sportswear Brands and Number of Followers on Twitter Pages.

\begin{tabular}{cccccc}
\hline$\#$ & $\begin{array}{c}\text { Large } \\
\text { Brands }\end{array}$ & $\begin{array}{c}\# \text { of } \\
\text { Followers }\end{array}$ & $\#$ & $\begin{array}{c}\text { Smaller } \\
\text { Brands }\end{array}$ & $\begin{array}{c}\# \text { of } \\
\text { Followers }\end{array}$ \\
\hline 1 & Nike & $8,367,659$ & 1 & Lotto & 11,596 \\
2 & Adidas & $3,866,455$ & 2 & Speedo & 50,068 \\
3 & Puma & $1,695,125$ & 3 & Umbro & 152,874 \\
4 & Reebok & 715,004 & 4 & Oakley & 364,817 \\
5 & Converse & $1,059,928$ & 5 & Diadora & 49,403 \\
6 & New Balance & 258,693 & 6 & Yonex & 41,095 \\
7 & Vans & $1,287,765$ & 7 & New Era & 213,004 \\
8 & Jordan & $4,164,203$ & 8 & Brooks & 224,124 \\
9 & Under & 950,670 & 9 & Lululemon & $1,002,607$ \\
10 & Armour & Champion & 47,723 & 10 & Hummel \\
\hline
\end{tabular}

\subsection{Modeling Approaches}

\subsubsection{Effect of Public-Issue Posts on Consumers' Active Reaction}

Two approaches are proposed to examine the effect of public-issue posts on consumers' active reaction. First, the effect is explored within the public-issue post sample using the self-constructed public-issue post index. Second, public-issue posts are compared against other general posts to investigate whether differences exist between the public-issue posts and other posts. Four dependent variables are consistent across both models and include: (a) \# of retweets, (b) \# of quotes, (c) \# of replies, and (d) post-social search behavior.

Proposed Model. The proposed model was developed using multiple regression analysis. Brand activeness and media type are included as additional independent variables to the regression analysis. The proposed model is as follows:

$$
y_{i j}=\alpha_{1}+\beta_{1}{\text { PIP } \text { Score }_{j}+\beta_{2} \text { BA }}_{k}+\beta_{3} \text { Photo }_{j}+\beta_{4} \text { Video }_{j}+\epsilon_{i j}
$$

$y_{i j}: y_{1 j}$ or $y_{2 j}$ or $y_{3 j}$ or $y_{4 j}$ : Consumer's active reaction-number of retweets, number of quotes, number of replies, and post-social search behavior per public-issue post $j(j=1 \ldots 143)$,

PIP Score $j$ : Public Issue Score Index based on 11 criteria (10 ESG scores and urgency of the issue) in post $j$,

$B A_{k}$ : Brand Activeness-number of public-issue posts tweeted by brand $\mathrm{k}$ in the reviewed period,

Photo $_{j}$ : Dummy variable whether a photo at post $j$ is included,

Video : Dummy variable whether a video at post $j$ is included,

$\epsilon_{\mathrm{ij}}: \epsilon_{1 \mathrm{j}}$ or $\epsilon_{2 \mathrm{j}}$ or $\epsilon_{3 \mathrm{j}}$ or $\epsilon_{4 \mathrm{j}}$ : Normally distributed error terms for dependent variables $y_{1 j}$ or $y_{2 j}$ or $y_{3 j}$ or $y_{4 j}$.

Extended Model. The extended model aims to explore the effect of public-issue posts on consumers' active reaction compared with other non-public-issue posts. Two interaction terms are included in the extended model. First, an interaction term between a public-issue post dummy and a public-issue post score is included. Assume that non-public-issue posts receive a score of 0 to compare the results between the proposed and extended models for public-issue posts and all other posts. Second, an interaction term between a publicissue post dummy and brand activeness is included to verify whether brand activeness in 
public-issue posts affects consumers' active reaction differently. The extended model has the following form:

$y_{i j}=\alpha_{2}+\gamma_{1}$ PIP Dummy $_{j} *$ PIP Score $j+\gamma_{2}$ BA $_{k}+\gamma_{3}$ PIP Dummy $j * B A_{k}+\gamma_{4}$ Photo $_{j}+\gamma_{5}$ Video $_{j}+\eta_{i j}$.

$y_{i j}: y_{1 j}$ or $y_{2 j}$ or $y_{3 j}$ or $y_{4 j}$ : Consumer's active reaction-number of retweets, number of quotes, number of replies, and post-social search behavior per public-issue post $j(j=1 \ldots 1476)$,

PIP Score $e_{j}$ Public Issue Score Index based on 11 criteria (10 ESG scores and urgency of the issue) in post $j$,

$B A_{k}$ : Brand Activeness-number of public-issue posts tweeted by brand $\mathrm{k}$ in the reviewed period,

Photo $j$ : Dummy variable whether a photo at post $j$ is included,

Video;: Dummy variable whether a video at post $j$ is included,

$\epsilon_{\mathrm{ij}}: \epsilon_{1 \mathrm{j}}$ or $\epsilon_{2 \mathrm{j}}$ or $\epsilon_{3 \mathrm{j}}$ or $\epsilon_{4 \mathrm{j}}$ : Normally distributed error terms for dependent variables $y_{1 j}$ or $y_{2 j}$ or $y_{3 j}$ or $y_{4 j}$.

\subsubsection{Variables for Analysis}

Independent variables. The independent variables used in this study are public-issue posts, brand activeness, and media type. An index was created to measure public-issue posts based on 11 checkpoints: 10 belong to the ESG dimensions (Table 2), and one which is a measure proposed for a study of ESG issues by Thomson Reuters [51]. According to Chabowsk et al. [52], a company can perform better when its activities are performed considering of all three dimensions of sustainability.

Table 2. Classification of ESG Dimensions.

\begin{tabular}{cc}
\hline Dimension & Classification \\
\hline \multirow{2}{*}{ Environmental } & Resource Use \\
& Emissions \\
& Innovation \\
\hline \multirow{2}{*}{ Social } & Workforce \\
& Human Rights \\
& Community \\
& Product Responsibility \\
\hline \multirow{2}{*}{ Governance } & Management \\
& Shareholders \\
& CSR Strategy \\
\hline
\end{tabular}

Based on this assumption, the proposed index suggests that the higher the ESG dimension score, the more consumers' active responses a tweet receives. Some of the issues mentioned in the tweets were more urgent regarding the events happening in the world (e.g., \#BlackLivesMatter) than others (e.g., yearly donation plan). Therefore, the urgency of a public issue was regarded as a crucial 11th point for the constructed public-issue post measure. A post was considered urgent if it discussed a current social or political issue or included an ongoing temporal event with a hashtag (e.g., \#breastcancermonth). Moreover, a public-issue post dummy is used in the extended model to compare public-issue and non-public-issue tweets.

Brand activeness is a variable describing the brand's social activity on Twitter and is measured as the number of public-issue posts tweeted by each of the 20 brands from a sample in the reviewed period. Media type is the last independent variable to be considered. This study investigates tweet media type by confirming the inclusion of a video or photo in each post.

Dependent variables. This study aims to investigate the active reaction of consumers toward public-issue posts. Accordingly, one of the most common Twitter metrics— "likes"- 
is not considered an active response because it does not require an extension of a tweet to one's Twitter page. Three active metrics-number of retweets, number of quotes, and number of replies-were crawled for each post and extracted into a dataset.

Furthermore, post-social search behavior is a newly constructed variable for this study to explore the after-post effect on consumers' active reaction. According to Elsweiler and Harvey [45], mentioning @links is one way to measure search behavior on Twitter. Given the importance of the freshness concept in social media searches, the constructed post-social search behavior metric is measured based on the number of brand mentions in the $24 \mathrm{~h}$ after the post was tweeted. This approach required the extraction of the brand mentions individually for each post, and due to its complexity, it was impossible to crawl data for all 1476 observations. The number of observations crawled for the post-social search behavior variable included 95 posts. Table 3 describes the independent and dependent variables used in this study.

Table 3. Variables and Descriptive Statistics.

\begin{tabular}{|c|c|c|c|c|c|c|c|c|c|}
\hline \multirow[t]{2}{*}{ Variable } & \multirow[t]{2}{*}{ Measures } & \multicolumn{4}{|c|}{ Sample $1^{1}$} & \multicolumn{4}{|c|}{ Sample $2^{2}$} \\
\hline & & Mean & SD & Min & Max & Mean & SD & Min & Max \\
\hline \multirow{4}{*}{$\begin{array}{l}\text { Active } \\
\text { Consumer } \\
\text { Reaction } \\
\text { (DV) }\end{array}$} & $y 1 j:$ Number of retweets of a post $j$ & 113.72 & 430.13 & 1 & 4220 & 31.64 & 141.11 & 0 & 4220 \\
\hline & $y 2 j:$ Number of quotes of a post $j$ & 13.22 & 41.10 & 0 & 394 & 4.94 & 14.90 & 0 & 394 \\
\hline & $y 3 j:$ Number of replies to a post $j$ & 22.69 & 78.04 & 0 & 702 & 7.18 & 26.01 & 0 & 702 \\
\hline & $\begin{array}{l}y 4 j: \text { Number of brand mentions in } 24 \mathrm{~h} \\
\text { after a tweet was posted }\end{array}$ & 333.46 & 531.85 & 7 & 3278 & 288.09 & 434.45 & 7 & 3278 \\
\hline \multirow{2}{*}{$\begin{array}{l}\text { Public } \\
\text { Issue Post } \\
\quad \text { (IV) }\end{array}$} & $\begin{array}{l}\text { PIP Dummy } \text { D }_{\text {D }} \text { Dummy if a post } \mathrm{j} \text { belongs to } \\
\text { public-issue post or non-public-issue post }\end{array}$ & 1 & 0 & 1 & 1 & 0.10 & 0.30 & 0 & 1 \\
\hline & 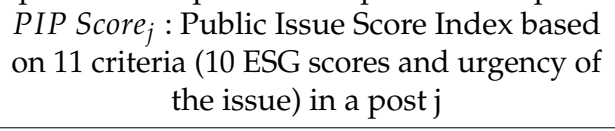 & 1.24 & 0.63 & 0 & 4 & 0.12 & 0.41 & 0 & 4 \\
\hline $\begin{array}{l}\text { Brand } \\
\text { Activeness } \\
\quad \text { (IV) }\end{array}$ & $\begin{array}{l}\text { Brand Activeness } s_{k}: \text { Number of } \\
\text { public-issue posts tweeted by the brand } \mathrm{k} \\
\text { in the reviewed period }\end{array}$ & 13.71 & 7.40 & 1 & 24 & 8.71 & 6.94 & 0 & 24 \\
\hline \multirow{2}{*}{$\begin{array}{l}\text { Media } \\
\text { Type } \\
\text { (IV) }\end{array}$} & $\begin{array}{c}\text { Photo }_{j} \text { : Dummy if a photo was included in } \\
\text { a post } j\end{array}$ & 0.36 & 0.48 & 0 & 1 & 0.57 & 0.49 & 0 & 1 \\
\hline & $\begin{array}{c}\operatorname{Video}_{j} \text { : Dummy if a video was included in } \\
\text { a post } \mathrm{j}\end{array}$ & 0.52 & 0.50 & 0 & 1 & 0.20 & 0.40 & 0 & 1 \\
\hline
\end{tabular}

${ }^{1} 143$ observations, ${ }^{2} 1476$ observations.

\section{Analysis Results}

\subsection{Results of Proposed Model}

A multiple regression analysis was performed to explore the effect of public-issue posts, brand activeness, and media type on the consumers' active reaction. Three hypotheses were developed and described previously. As depicted in Equation (1), the results of the proposed model are presented in Table 4.

$\mathrm{H} 1$ aimed to verify that public-issue posts have a positive effect on consumer reaction. As the results reveal, the effect of the public-issue post score is significant and positive for all four variables. Consequently, the higher the public-issue post score, the more likely consumers are to respond to the tweets by retweeting $(\beta=171.125, p<0.01)$, quoting $(\beta=17.557, p<0.01)$, replying to posts $(\beta=30.943, p<0.01)$, and mentioning a brand's name during the next $24 \mathrm{~h}(\beta=290.242, p<0.01)$.

$\mathrm{H} 2$ suggested that brand activeness has a positive effect on consumers' active reaction. The linear regression model revealed a significant but negative correlation between brand activeness and the four dependent variables, which is not consistent with the suggested direction of the relationship. Further investigation is required to verify the reasons for the opposite effect of brand activeness on the quantitative metrics of a public-issue post. 
The following analysis of the extended model will attempt to explore the reasons for the opposite direction.

Table 4. Results of Proposed Model.

\begin{tabular}{ccccc}
\hline & \multicolumn{3}{c}{ Active Consumer Reaction } \\
\cline { 2 - 4 } & \# of Retweets & \# of Quotes & \# of Replies & Post-Social Search Behavior \\
\hline Public-issue post score & $171.125^{* * *}$ & $17.557^{* * *}$ & $30.943^{* * *}$ & $290.242^{* * *}$ \\
Brand activeness & $-8.428^{*}$ & $-1.142^{* *}$ & $-2.657^{* * *}$ & $-27.621^{* * *}$ \\
Photo & 75.513 & 3.594 & 13.451 & 261.281 \\
Video & 2.628 & 7.846 & 12.566 & 190.782 \\
\hline R-square & 0.089 & 0.116 & 0.126 & 0.323 \\
AIC & 1729.965 & 1054.089 & 1235.874 & 665.810 \\
BIC & 1744.779 & 1068.903 & 1250.688 & 675.755 \\
\hline
\end{tabular}

Notes: ${ }^{*} p<0.10,{ }^{* *} p<0.05,{ }^{* * *} p<0.01$.

H3 proposed that the tweet media type studied based on the inclusion of a photo or video has a positive effect on consumers' active reaction. This hypothesis could not find support because the results demonstrate a non-significant relationship between the media type and all four dependent variables.

\subsection{Results of Extended Model}

After analyzing the primary effect of a public-issue post within the public-issue post sample exclusively, another analysis using the extended dataset was conducted. The second approach includes all tweets posted by the considered 20 brands over six months and explores the differences between public-issue and non-public-issue posts. The results of the extended model are presented in Table 5. An interaction term between the public-issue post dummy and public-issue post score explores whether the effect of public-issue post score has a stronger positive relationship in public-issue posts compared with other posts. As the results demonstrate, the effect of public-issue post score is stronger in public-issue posts across all four sub-models.

Table 5. Results of Extended Model.

\begin{tabular}{ccccc}
\hline & \multicolumn{4}{c}{ Active Consumer Reaction } \\
\cline { 2 - 5 } & \# of Retweets & \# of Quotes & \# of Replies & Post-Social Search Behavior \\
\hline PIP Dummy * PIP Score & $231.051^{* * *}$ & $24.436^{* * *}$ & $54.062^{* * *}$ & $336.839^{*}$ \\
Brand Activeness & $0.989^{*}$ & $0.113^{*}$ & 0.118 & -11.580 \\
PIP Dummy * Brand Activeness & $-10.532^{* * *}$ & $-1.177^{* * *}$ & $-2.758^{* * *}$ & -17.316 \\
Photo & -9.671 & 0.088 & -2.317 & 99.907 \\
Video & -9.972 & 0.723 & -0.815 & 142.836 \\
\hline R-square & 0.064 & 0.062 & 0.094 & 0.181 \\
AIC & 14525.119 & 7891.658 & 9483.724 & 1134.184 \\
BIC & 14556.901 & 7923.440 & 9515.506 & 1149.443 \\
\hline
\end{tabular}

Notes: ${ }^{*} p<0.10,{ }^{* * *} p<0.01$.

In the first part of the empirical analysis, the proposed model confirmed that the effect of brand activeness on consumers' active reaction had a negative sign against the proposed direction, but the underlying cause remained unanswered. The coefficient of the brand activeness effect on consumers' active reaction in the extended model is positive for three of the four variables (\# of retweets, quotes, and replies), two of which illustrate a significant relationship. However, when verifying the interaction term between the public-issue post dummy and brand activeness, a negative relationship appears repeatedly.

This result suggests that, for general posts, brand activeness significantly increases the number of retweets and quotes of branded tweets. In contrast, in public-issue posts, brand 
activeness may decrease the number of consumer reactions. Brands should be cautious about the number of tweets they produce on public issues. As described previously, the post-social search behavior metric incorporated significantly fewer observations than the rest of the sample, suggesting that the current results for this variable should be verified on a larger sample. Moreover, the goodness of fit indicates that the proposed model is more reliable than the extended model.

\section{Discussion}

According to previous research on brand communication $[43,53,54]$, social media has become one of the most effective communication channels for brands. Thus, brands have attempted to establish communication strategies with customers through social media platforms based on brand- or product-related content [16]. Moreover, brands have recently voiced their opinions and emotions on public issues to demonstrate their commitment and communicate with customers through social content as if they were people [35,36]. Sarkar and Kotler [9] mentioned that changes in brand communication strategies on social media relate to the concept of brand activism. Brands engage in brand activism to differentiate themselves from other brands under consumers' needs and, as a result, aim to increase consumers' positive reaction and their equity value $[10,11]$. In this brand communication and brand activism context, the current research explores the effect of public issue posts on consumer active reactions on brands' official Twitter pages. The results of empirical studies revealed that public-issue posts have a positive effect on four types of consumers' active reactions $(\mathrm{H} 1)$, and the results of the extended model analysis demonstrated that publicissue posts have a stronger effect over other general posts. The findings have quantitative implications that demonstrate the efficacy of communication methods in which brands take public positions via social media.

In quantitative studies on consumer social engagement, a brand's social media activity is one of the crucial antecedent variables [22,47]. However, since this research is focused on public-issue posts, the effect of brand activeness, which is defined as the state of a brand being socially active on Twitter, on consumer active reaction is examined. The findings revealed that brand activeness has a negative impact on four types of consumer active reactions, which is not consistent with the suggested hypothesis ( $\mathrm{H} 2)$. This is explained by the results of the extended model analysis. Three of the four variables (\# of retweets, quotes, and replies) have positive coefficients of the brand activeness effect on consumers' active reactions in the extended model, two of which show a significant relationship. This changed result is consistent with previous research showing that active social media activities (e.g., number of posts, number of interactions, and average response time to inquiries, to name a few, etc.) impact consumer reactions positively $[47,55]$.

The interaction term between public-issue post-dummy and brand activeness, on the other hand, continues to have a negative influence on consumer active response. In other words, in the case of public issue posts, simply uploading many posts may have a poisonous effect on customer communication. Vredenburg et al. [10] mentioned that brand activism could be an emerging marketing communication strategy for brands seeking to stand out in the marketplace. Yet, they also emphasized that taking a public stance on public issues is never simple [56]. Mirzaei et al. [57] pointed out that consumers are turned off by a brand's indiscriminate and insincere response to public issues. Some brands have been accused of exploiting current and trending social issues by jumping on the "woke" bandwagon $[10,57]$. In this context, the findings show the possibility that simply posting many posts on public issues without being sincere could harm consumers' perceptions of brand authenticity.

The effect of media presence (photo or video) in a Tweet on consumers' active reactions is also considered in this study. However, the results show no significant impact of the media types on consumers' active reactions (H3). The findings suggest that the content is more important than how it is delivered in the tweets concerning public issues, and that 
the public issue post score variable has a greater impact on consumers' active reactions than other variables.

\section{Conclusions and Implication}

Our study aimed to investigate the effect of public-issue posts on consumers' active reaction. In the modern world, where brands more actively take a stand on social and political issues by expressing their opinion online while shaping their personality, this study offers some guidelines on dealing with public-issue posts on Twitter. Several meaningful implications are apparent from exploring the effect of public-issue posts on the number of retweets, number of quotes, number of replies, and post-social search behavior.

First, an index to measure public-issue posts is proposed relying on ESG dimensions previously examined only at the corporate level. ESG criteria were applied to a single post level in this study and integrated with the urgency of public-issue tweets contributing to the ESG literature.

Second, the effect of public-issue posts on four types of consumers' active reactions was explored. The results of the two models verified the hypothesis that the higher the public issue score of a post, the more active the consumer reactions. The effect of a publicissue post score was stronger for public-issue posts than other general posts. This study is significant because it established a quantitative foundation for re-establishing brand communication strategies by demonstrating the effectiveness of communication methods in which brands take a public stance through social media.

Third, the effect of brand activeness and media type was examined. Although the relationships between photo or video inclusion and consumer reactions are insignificant for all posts, the effect of brand activeness exhibited a remarkable result. Tweeting more on social issues has a positive effect on the number of retweets and quotes in all posts on Twitter. However, in public-issue posts, brand activeness conversely led to a negative outcome.

Consequently, mentioning ESG dimensions and taking a stand on urgent ongoing social issues on official Twitter pages might improve consumer engagement with a brand and boost online communication interactive platforms such as Twitter. However, taking an open stand on controversial issues might also have a reverse effect, such as when a brand tweets too much on public issues or does not diversify its Twitter content strategy with different types of content. A common suggestion for brands of all scales is to account for the quality of their posts and analyze the interactions with users under the posts to provide a balanced ratio of informational and entertaining content.

\section{Limitation and Suggestion for Future Research}

Previous research explored different types of branded tweets and tactics used by brands. For instance, some common types of tweets include information-sharing, endorsing a topic, broadcasting, opinion-sharing, and private messaging [58-60]. Although it is not clear which types of tweets lead to higher consumer engagement than public-issue posts, a suggestion for future research might be to segment posts into categories and verify the differences between them.

The 20 brands examined in this study engaged in highly distinct Twitter posting strategies. For some brands, like Nike and Adidas, consumer reactions have always been high due to the brand power. Some brands, like Vans and New Era Cap, have been very active on Twitter but could not reach high engagement numbers. Some brands did not tweet on public issues and preferred more traditional posts. Future research could explore the strategies exhibited by brands and the differences between brands of different sizes.

Another aspect addressed in previous literature that this study does not account for is inauthentic brand activism, which may lead to consumers neglecting the brand [10]. Classifying tweets on a negative to positive spectrum will help to provide a more sophisticated analysis and answer the research question, such as which brands get neglected and which are favored for taking a stand on public issues. 
Author Contributions: Conceptualization, A.B., D.-Y.K. and S.-Y.K.; Data curation, A.B., D.-Y.K. and S.-Y.K.; Investigation, A.B.; Methodology, D.-Y.K.; Project administration, S.-Y.K.; Supervision, S.-Y.K.; Validation, D.-Y.K.; Writing—original draft, A.B.; Writing—review \& editing, D.-Y.K. and S.-Y.K. All authors have read and agreed to the published version of the manuscript.

Funding: This research was financially supported by Korea University Business School Research Grant (K2107971).

Institutional Review Board Statement: Not applicable.

Informed Consent Statement: Not applicable.

Data Availability Statement: Publicly available datasets were analyzed in this study. This data can be found here: https:/ / twitter.com (accessed on 5 October 2021).

Conflicts of Interest: The authors declare no conflict of interest.

\section{References}

1. Xu, A.; Liu, H.; Gou, L.; Akkiraju, R.; Mahmud, J.; Sinha, V.; Hu, Y.; Qiao, M. Predicting perceived brand personality with social media. In Proceedings of the Tenth International AAAI Conference on Web and Social Media, ICWSM 2016, Cologne, Germany, 17-20 May 2016; pp. 436-445.

2. Sprout Social. Brands Creating Change in the Conscious Consumer Era. 2019. Available online: https://sproutsocial.com/ insights / data/brands-creating-change (accessed on 5 October 2021).

3. Johnson, A.R.; Thomson, M.; Jeffrey, J. What does brand authenticity mean? Causes and consequences of consumer scrutiny toward a brand narrative. Rev. Mark. Res. 2015, 12, 1-27. [CrossRef]

4. McGraw, T. Spending 2020 Together on Twitter. Available online: https://blog.twitter.com/en_us/topics/insights/2020 /spending-2020-together-on-twitter (accessed on 5 October 2021).

5. Twitter Trends One Planet: The Conversation Twitter Trends. Available online: https://marketing.twitter.com/en/insights/theconversation-twitter-trends-2021/one-planet (accessed on 18 March 2021).

6. Twitter Marketing Beauty on Twitter: Start with the Ones Who Defy Convention. Available online: https://marketing.twitter. com/en/insights/beauty-on-twitter-start-with-the-ones-who-defy-convention (accessed on 18 March 2021).

7. Elizabeth, M.; Wayne, H. Ready to LAUNCH? Why You Should Turn to Twitter. Available online: https://marketing.twitter.com/ en/insights/ready-to-launch-why-you-should-turn-to-twitter (accessed on 18 March 2021).

8. Altman, B.W. Transformed Corporate Community Relations: A Management Tool for Achieving Corporate Citizenship 1. Bus. Soc. Rev. 1999, 102-103, 43-51. [CrossRef]

9. Sarkar, C.; Kotler, P. Brand Activism from Purpose to Aciton, 2nd ed.; IDEA BITE PRESS: Houston, TX, USA, 2020; Volume 1, ISBN 1734244119.

10. Vredenburg, J.; Kapitan, S.; Spry, A.; Kemper, J.A. Brands Taking a Stand: Authentic Brand Activism or Woke Washing? J. Public Policy Mark. 2020, 39, 444-460. [CrossRef]

11. El Zein, S.A.; Consolacion-Segura, C.; Huertas-Garcia, R. The role of sustainability in brand equity value in the financial sector. Sustainability 2020, 12, 254. [CrossRef]

12. Kemper, J.A.; Ballantine, P.W. What do we mean by sustainability marketing? J. Mark. Manag. 2019, 35, 277-309. [CrossRef]

13. Wong, V.; Turner, W.; Stoneman, P. Marketing strategies and market prospects for environmentally-friendly consumer products. Br. J. Manag. 1996, 7, 263-281. [CrossRef]

14. Carrigan, M.; Attalla, A. The myth of the ethical consumer-Do ethics matter in purchase behaviour? J. Consum. Mark. 2001, 18, 560-578. [CrossRef]

15. Jungblut, M.; Johnen, M. When Brands (Don't) Take My Stance: The Ambiguous Effectiveness of Political Brand Communication. Communic. Res. 2021, 1, 1-26. [CrossRef]

16. Mukherjee, S.; Althuizen, N. Brand activism: Does courting controversy help or hurt a brand? Int. J. Res. Mark. 2020, 37, 772-788. [CrossRef]

17. Barnes, N.G.; Pavao, S.; Fernandes, B. Research: The Fortune 500 Adapt to the Sudden and Unprecedented COVID-19 Global Pandemic. I Center for Marketing Research I UMass Dartmouth. Available online: https://www.umassd.edu/cmr/research/ how-the-pandemic-impacted-social-media-use-among-the-fortune-500.html (accessed on 5 October 2021).

18. Kaplan, A.M.; Haenlein, M. Users of the world, unite! The challenges and opportunities of Social Media. Bus. Horiz. 2010, 53, 59-68. [CrossRef]

19. Kwon, E.S.; Sung, Y. Follow Me! Global Marketers' Twitter Use. J. Interact. Advert. 2011, 12, 4-16. [CrossRef]

20. Heaps, D. Twitter: Analysis of Corporate Reporting Using Social Media. Corp. Gov. Advis. 2009, 17, 18-23.

21. Xu, S.; Zhou, A. Hashtag homophily in twitter network: Examining a controversial cause-related marketing campaign. Comput. Human Behav. 2020, 102, 87-96. [CrossRef]

22. Soboleva, A.; Burton, S.; Khan, A. Marketing with Twitter: Challenges and Opportunities; IGI Global: Hershey, PA, USA, 2015; ISBN 9781466684096. 
23. Suh, B.; Hong, L.; Pirolli, P.; Chi, E.H. Want to be retweeted? Large scale analytics on factors impacting retweet in twitter network. In Proceedings of the 2010 IEEE Second International Conference on Social Computing, Minneapolis, MN, USA, 20-22 August 2010; pp. 177-184. [CrossRef]

24. Canhoto, A.I.; Clark, M. Customer service 140 characters at a time: The users' perspective. J. Mark. Manag. 2013, $29,522-544$. [CrossRef]

25. Lou, C.; Tan, S.S.; Chen, X. Investigating Consumer Engagement with Influencer- vs. Brand-Promoted Ads: The Roles of Source and Disclosure. J. Interact. Advert. 2019, 19, 169-186. [CrossRef]

26. Wood, N.T.; Burkhalter, J.N. Tweet this, not that: A comparison between brand promotions in microblogging environments using celebrity and company-generated tweets. J. Mark. Commun. 2014, 20, 129-146. [CrossRef]

27. Dann, S. Twitter Content Classification. First Monday 2010, 15. [CrossRef]

28. Hohl, M. Beyond the screen: Visualizing visits to a website as an experience in physical space. Vis. Commun. 2009, 8, 273-284. [CrossRef]

29. Henneberg, S.C.; Scammell, M.; O'Shaughnessy, N.J. Political marketing management and theories of democracy. Mark. Theory 2009, 9, 165-188. [CrossRef]

30. Steiner, H. Reference utility of social networking sites: Options and functionality. Libr. Hi Tech News 2009, 26, 4-6. [CrossRef]

31. Kwon, E.S.; Kim, E.; Sung, Y.; Yoo, C.Y. Brand followers: Consumer motivation and attitude towards brand communications on Twitter. Int. J. Advert. 2014, 33, 657-680. [CrossRef]

32. Guthrie, S.E. Faces in the Clouds: A New Theory of Religion; Oxford University Press: New York, NY, USA; Oxford, UK, 1995.

33. Caporeal, L.R.; Heyes, C.M. Why anthropomorphize? Folk Psychology and Other Stories. In Anthropomorphism, Anecdotes, and Animals; University of New York Press: Albany, NY, USA, 1997; pp. 59-73. ISBN 978-0791431269.

34. Aaker, J.L. Dimensions of Brand Personality. J. Mark. Res. 1997, 34, 347-356. [CrossRef]

35. Sashittal, H.C.; Hodis, M.; Sriramachandramurthy, R. Entifying your brand among Twitter-using millennials. Bus. Horiz. 2015, 58, 325-333. [CrossRef]

36. Yun, J.T.; Pamuksuz, U.; Duff, B.R.L. Are we who we follow? Computationally analyzing human personality and brand following on Twitter. Int. J. Advert. 2019, 38, 776-795. [CrossRef]

37. Muñoz-Expósito, M.; Oviedo-García, M.Á.; Castellanos-Verdugo, M. How to measure engagement in Twitter: Advancing a metric. Internet Res. 2017, 27, 1122-1148. [CrossRef]

38. Ingrassia, M.; Altamore, L.; Bacarella, S.; Columba, P.; Chironi, S. The wine influencers: Exploring a new communication model of open innovation for wine producers-A netnographic, factor and AGIL analysis. J. Open Innov. Technol. Mark. Complex. 2020, 6, 165. [CrossRef]

39. Saboo, A.R.; Kumar, V.; Ramani, G. Evaluating the impact of social media activities on human brand sales. Int. J. Res. Mark. 2016, 33, 524-541. [CrossRef]

40. Kim, E.; Sung, Y.; Kang, H. Brand followers' retweeting behavior on Twitter: How brand relationships influence brand electronic word-of-mouth. Comput. Human Behav. 2014, 37, 18-25. [CrossRef]

41. Sotiropoulos, K.; Byers, J.W.; Pratikakis, P.; Tsourakakis, C.E. TwitterMancer: Predicting User Interactions on Twitter. In Proceedings of the 2019 Annual Allerton Conference on Communication, Control, and Computing (Allerton), Monticello, IL, USA, 24-27 September 2019; pp. 973-980. [CrossRef]

42. Machleit, K.A.; Madden, T.J.; Allen, C.T. Measuring and modeling brand interest as an alternative ad effect with familiar brands. ACR North Am. Adv. 1990, 17, 223-230.

43. Gao, X.; Kim, S.Y.; Kim, D.Y.; Lee, S.M. The Effects of Social Media Advertising on Social Search in China: Evidence from Luxury Brand. Asia Mark. J. 2019, 21. [CrossRef]

44. Richins, M.L. Word of Mouth Communication as Negative Information. Adv. Consum. Res. 1984, 11, 697-702.

45. Elsweiler, D.; Harvey, M. Engaging and Maintaining a Sense of Being Informed: Understanding the Tasks Motivating Twitter Search. J. Assoc. Inf. Sci. Technol. 2015, 66, 264-281. [CrossRef]

46. Mishne, G.; De Rijke, M. A study of blog search. In Proceedings of the Lecture Notes in Computer Science (Including Subseries Lecture Notes in Artificial Intelligence and Lecture Notes in Bioinformatics), London, UK, 10-12 April 2006; Volume 3936 LNCS, pp. 289-301.

47. Aichner, T.; Jacob, F. Measuring the degree of corporate social media use. Int. J. Mark. Res. 2015, 57, 257-275. [CrossRef]

48. Han, X.; Gu, X.; Peng, S. Analysis of Tweet Form's effect on users' engagement on Twitter. Cogent Bus. Manag. 2019, 6, 1564168. [CrossRef]

49. Brooks, A. 15 Twitter Business Statistics \& Trends on Twitter Advertising. Available online: https://www.ventureharbour.com/ twitter-business-statistics-trends-on-twitter-advertising/ (accessed on 5 October 2021).

50. Global Web Index GlobalWebIndex Core Survey I Brand List Q1 2021: Have You Purchased Anything from These Sports Brands? 2021. Available online: https://f.hubspotusercontent20.net/hubfs/304927/resources-page/Content/Q1\%202021/Q1\%20202 1\%20Core\%20Survey\%20-\%20Brand\%20List.pdf (accessed on 5 October 2021).

51. Thomson Reuters Thomson Reuters ESG Scores. 2017. Available online: https://www.esade.edu/itemsweb/biblioteca/bbdd/ inbbdd/archivos/Thomson_Reuters_ESG_Scores.pdf (accessed on 5 October 2021).

52. Chabowski, B.R.; Mena, J.A.; Gonzalez-Padron, T.L. The structure of sustainability research in marketing, 1958-2008: A basis for future research opportunities. J. Acad. Mark. Sci. 2011, 39, 55-70. [CrossRef] 
53. Voorveld, H.A.M. Brand Communication in Social Media: A Research Agenda. J. Advert. 2019, 48, 14-26. [CrossRef]

54. Appel, G.; Grewal, L.; Hadi, R.; Stephen, A.T. The future of social media in marketing. J. Acad. Mark. Sci. 2020, 48, 79-95. [CrossRef]

55. Hudson, S.; Huang, L.; Roth, M.S.; Madden, T.J. The influence of social media interactions on consumer-brand relationships: A three-country study of brand perceptions and marketing behaviors. Int. J. Res. Mark. 2016, 33, 27-41. [CrossRef]

56. Moorman, C. Commentary: Brand Activism in a Political World. J. Public Policy Mark. 2020, 39, 388-392. [CrossRef]

57. Mirzaei, A.; Wilkie, D.C.; Siuki, H. Woke brand activism authenticity or the lack of it. J. Bus. Res. 2022, 139, 1-12. [CrossRef]

58. Boyd, D.; Golder, S.; Lotan, G. Tweet, tweet, retweet: Conversational aspects of retweeting on twitter. In Proceedings of the 2010 43rd Hawaii International Conference on System Sciences, Honolulu, HI, USA, 5-8 January 2010; pp. 1-10. [CrossRef]

59. Naaman, M.; Boase, J.; Lai, C.-H. Is it really about me? In Proceedings of the 2010 ACM Conference on Computer Supported Cooperative Work, Savanna, GA, USA, 6-10 February 2010; pp. 189-192. [CrossRef]

60. Sridevi, P.; Niduthavolu, S.; Vedanthachari, L.N. Analysis of content strategies of selected brand tweets and its influence on information diffusion. J. Adv. Manag. Res. 2020, 18, 227-249. [CrossRef] 